\title{
Transcatheter closure of post myocardial Infarction ventricular septal rupture with the Amplatzer Septal occluder
}

\author{
Chandra Mani Adhikari', Manish Shrestha ${ }^{2}$, Birat Timalsina ${ }^{1}$, Amrit Bogati ${ }^{1}$, Madhu Rokka ${ }^{1}$, \\ Kiran Acharya ${ }^{1}$, Dipanker Prajapati ${ }^{1}$, Dharmanath Yadav ${ }^{1}$, Ashish Gopal Amatya ${ }^{3}$
}

${ }^{1}$ Department of Cardiology, Shahid Gangalal National Heart Centre, Kathmandu, Nepal

${ }^{2}$ Department of Paediatric Cardiology, Shahid Gangalal National Heart Centre, Kathmandu, Nepal

${ }^{3}$ Department of Anaesthesia, Shahid Gangalal National Heart Centre, Kathmandu, Nepal

Corresponding Author: Chandra Mani Adhikari

Department of Cardiology, Shahid Gangalal National Heart Centre, Kathmandu, Nepal

Email: cmadhikari@sgnhc.org.np

ORCID ID NO: 0000-0001-5811-9977

Cite this article as: Adhikari C. M., Shrestha M., Timalsina B., et al. Transcatheter closure of post myocardial Infarction ventricular septal rupture with the Amplatzer Septal occluder. Nepalese Heart Journal 2021; Vol 18(2), 65-68.

Submission date: $19^{\text {th }}$ August, 2021

Accepted date: $28^{\text {th }}$ September, 2021

Abstract

\begin{abstract}
Ventricular septal rupture is a rare yet life threatening complication of acute myocardial infarction. Surgical closure is the treatment of choice however despite surgical intervention mortality remains high. Transcatheter closure of ventricular septal rupture has emerged as a new alternative strategy which is less invasive procedure, potentially allows early hemodynamic stabilization. We report a case of a 60 -year-old male with post infarction ventricular septal rupture who was treated with percutaneous closure with Amplatzer device at Shahid Gangalal National Heart Center, Nepal.
\end{abstract}

Keywords: Myocardial Infarction, Ventricular Septal Rupture, Interventional Closure, Amplatzer Septal occluder Device.

DOI: https://doi.org/10.3126/njh.v18i2.40408

\section{Introduction}

Ventricular septal rupture (VSR) is an uncommon but potentially fatal complication of acute myocardial infarction (AMI) ${ }^{1}$. Historically the incidence of VSR was about $1-2 \%$ but recent data suggest that it complicates $0.17-0.31 \%$ of $\mathrm{AMI}^{2}$.

Guidelines of the American College of Cardiology and American Heart Association recommends immediate surgical correction regardless of the patient's haemodynamic status ${ }^{3}$. Despite modern surgical techniques, specialized cardiac anesthesia and myocardial protection during cardiac surgery, surgical outcomes remain poor and mortality is high ${ }^{1,4,5}$. In recent years, transcatheter closure of VSR has been proposed as an alternative to surgical repair as it is less invasive and might allow for immediate complete VSD closure allowing initial hemodynamic stabilization ${ }^{6}$.
Herein, we report a case of a 60 -year-old male with post infarction VSR who was treated with percutaneous closure using an Amplatzer septal occluder device.

\section{Case Report}

A 60-year-old diabetic male was referred to our hospital with the diagnosis of acute extensive anterior wall ST elevation myocardial infarction and VSR. He had chest pain three days before presentation to our hospital. Due to late presentation at the local hospital he was not given the reperfusion therapy.

Electrocardiography (ECG) showed right bundle branch block with ST-segment elevation in the precordial leads consistent with acute extensive anterior wall ST elevation myocardial infarction as shown in Figure 1. 


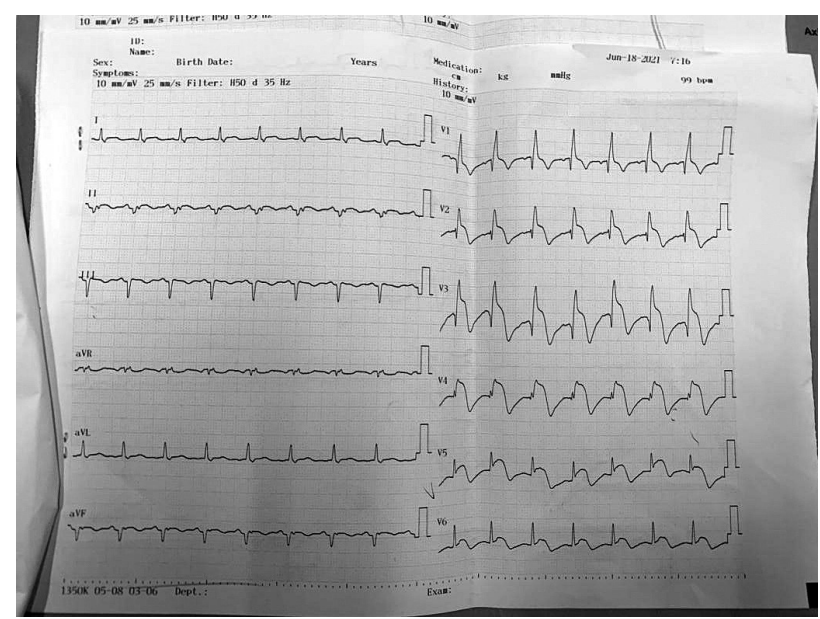

Figure 1: ECG at presentation

At presentation patient's blood pressure was $100 / 60 \mathrm{~mm} \mathrm{Hg}$ and pulse was 100 beats per minute. Precordial examination revealed a pansystolic murmur at the left sternal border. Echocardiography showed akinetic apical and anterior segments, with moderately impaired left ventricular function $(\mathrm{LVEF}=35 \%)$ and a $15 \mathrm{~mm}$ Apical VSR as shown in Figure 2.

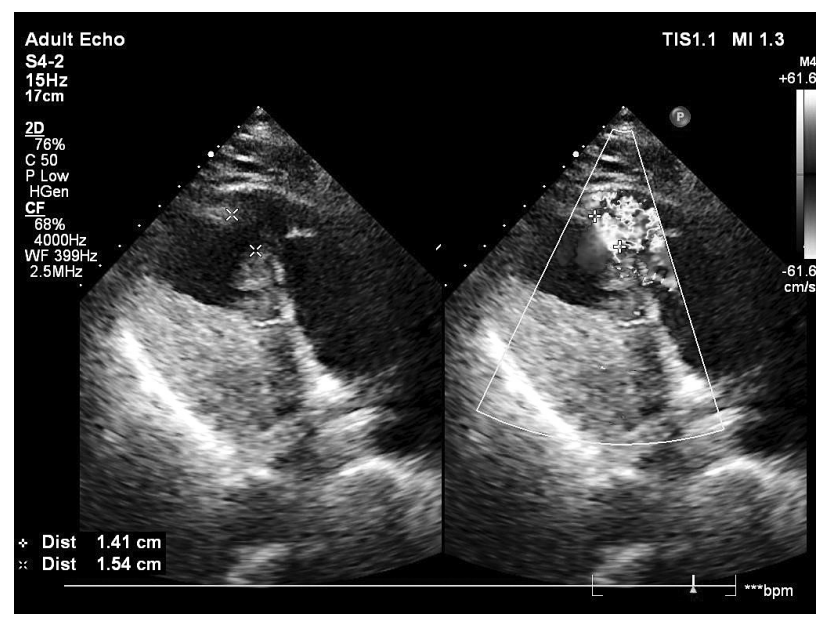

Figure 2: Apical VSR of $15 \mathrm{~mm}$.

After an informed consent, patient was taken to cardiac catheterization laboratory for transcatheter closure of VSR. The procedure was performed under transthoracic echocardiography and fluoroscopy guidance under local anesthesia. The right femoral artery and right internal jugular vein were accessed and $3000 \mathrm{U}$ heparin was immediately given. A left ventriculography was performed in left anterior oblique $60^{\circ}$ and cranial $30^{\circ}$ angulation with 6 French Pigtail catheter which showed $15 \mathrm{~mm}$ VSR as shown in Fig 3.

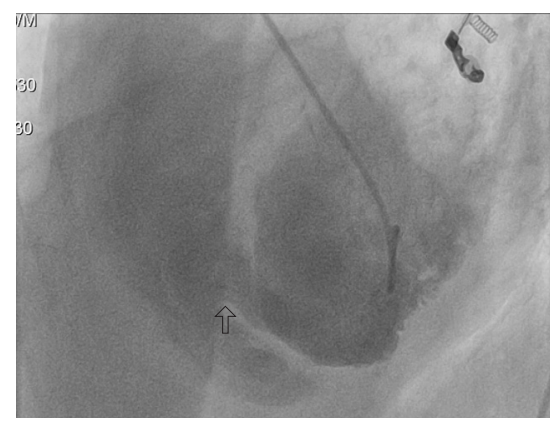

Figure 3: LV angiogram in $\mathrm{LAO} 60^{\circ}$ Cranial $30^{\circ}$
The VSR was crossed in a retrograde fashion from the left ventricle using Judkins right catheter and an exchange length floppy terumo guidewire. The wire was advanced into the inferior vena cava and was then snared with gooseneck snare to establish an arteriovenous circuit through right internal jugular vein. An appropriate size dilator and long sheath was advanced into the left ventricle through the arteriovenous circuit and positioned in the left ventricle. A $30 \mathrm{~mm}$ Amplatzer ${ }^{\circledR}$ septal Occluder (AGA Medical, Plymouth, Minnesota) was screwed on the delivery cable and was passed through the delivery sheath. The distal disc was deployed in left ventricle and the whole system was withdrawn. The proximal disc was unsheathed in the right ventricle after confirming that the left ventricular disc was in the correct position as shown in figure 4 and 5 .

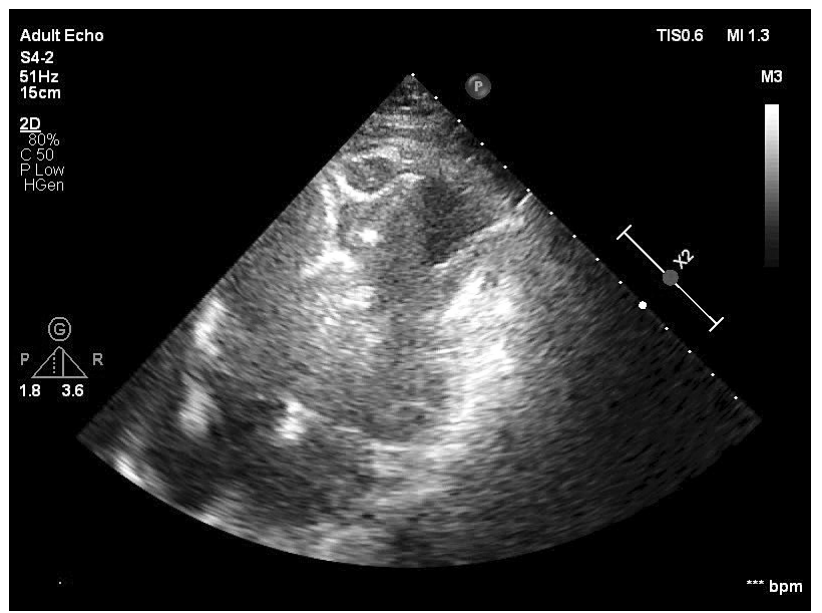

Figure 4: Echocardiogram with device

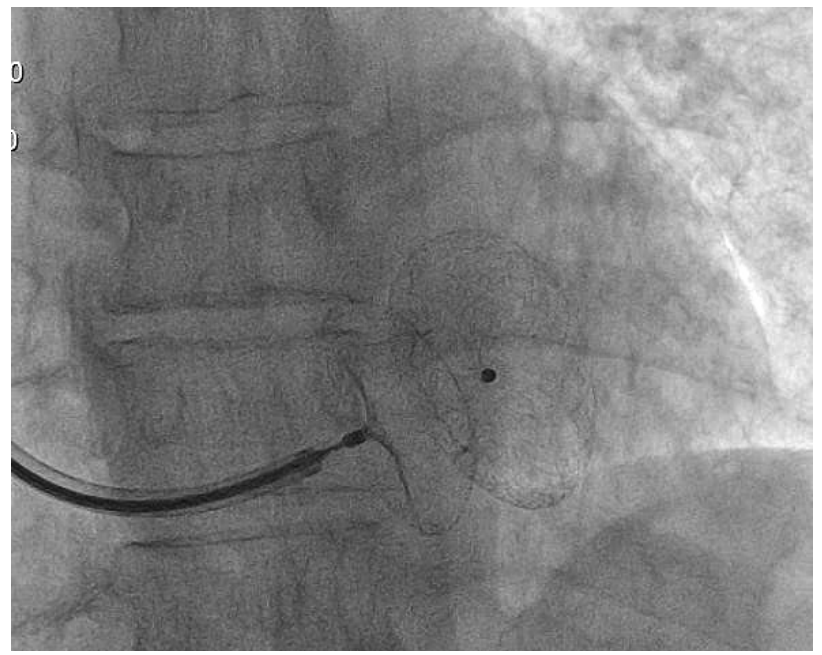

Figure 5: Amplatzer septal occluder with delivery cable.

Left ventriculography done after device deployment showed persistent mild left to right shunt. After completion of procedure patient was transferred to coronary care unit. The patient's hemodynamics remained stable for 4 hours after the procedure. However, 4 hours after procedure patient developed hypotension. He was started on ionotropic support. Transthoracic echocardiography was done to confirm the position of device, which showed the device in situ correctly positioned across the VSR. Other possible 
complications including retroperitoneal hematoma was sought for but there were no such complications. Six hours after the procedure patient developed cardiac arrest, and died despite advanced resuscitation maneuvers. Transthoracic echocardiography was done to confirm the position of device.

\section{Discussion}

Guidelines suggest that early surgical repair is the definitive option for post-infarction VSR. The mortality of surgical intervention within 24 hours of AMI is over sixty percent. In contrast, the untreated ventricular septal rupture has a mortality of $40 \%$ to $80 \%$. Due to the significant perioperative risk $^{8,9}$, many surgeons prefer to delay surgical VSD repair at least by two weeks to allow initial healing, firmer anchoring of suture and better support for patch

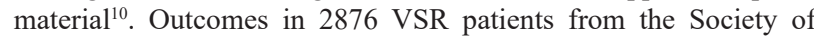
Thoracic Surgeons National Database who managed surgically were reported by Arnaoutakis et $\mathrm{al}^{4}$. They stated that operative mortality was $54.1 \%(1077 / 1990)$ if repair was $\leq 7$ days from MI, and $18.4 \%$ $(158 / 856)$ if $>7$ days from MI and they concluded that VSR remains a devastating complication after MI. Common practice is to delay surgery and many of these patients are not treated ${ }^{11}$.

Percutaneous closure of post-infarct VSR was first reported in 1980s. Since then improvement in device technology has been achieved ${ }^{12}$. The transcatheter approach to close post-infarct VSR is reserved to high-surgical-risk patients, in cardiogenic shock, failed surgery, or VSR with difficult site to allow surgical closure $^{13}$. Percutaneous closure results in favorable short and longterm outcomes for VSR patients ${ }^{14}$. In recent years, transcatheter closure of post-infarction VSR has become good alternative to surgical repair and even to the conservative approach. Advantage of transcatheter approach is a less invasive option which allows for immediate complete defect closure and also aids in initial hemodynamic stabilization ${ }^{6}$. However, experience in percutaneous closure of postinfarction VSR is very limited and restricted to highly selective patients ${ }^{8,9}$. Survival rates following surgical closure in this context are equally disappointing ${ }^{15}$. In the series by Thiele et al., 30-day mortality following surgical closure was significantly high. Mortality was very high among those patients who presented with shock versus without shock ( 88 vs. $38 \%)^{16}$.

In our case, as patients was not given the reperfusion therapy, he was at high risk for the development of VSR. Once VSR developed, early transcatheter closure of VSR was successfully performed within 2 weeks of development of VSR. Data shows that the mortality associated with delayed percutaneous closure $(\geq 2$ weeks after VSR detection) is $6.1-10.0 \%{ }^{17,18}$ while mortality after early closure $(<2$ weeks after VSR occurrence) is as high as $66 \% 14,16$. However in a large number of patients, it is not possible to delay the closure as they are at very high risk of developing severe heart failure and organ dysfunction ${ }^{15,19}$. Hence, in our case despite patient was hemodynamically stable at the time of presentation, we did not delay the transcatheter closure of VSR. In our case coronary intervention was not performed along with VSR closure. This strategy is supported in other case report too. It is thought that coronary lesion should be addressed on later date for better results and primary focus should be on correction of mechanical complication ${ }^{20}$.

In our case patient remained hemodynamically stable for four hours. But patient died after six hours of device implantation. The death could be due to natural cause after acute MI. It is suggested that even those patients who underwent a successful device closure of the VSR often succumb to antecedent causes. The post VSR closure course in the intensive coronary care unit is often stormy and requires careful monitoring to detect complications early and manage them appropriately ${ }^{20}$. Transcatheter device closure of VSR has a high technical success rate with a relatively low complication rate; however, it is associated with high in-hospital mortality rates when performed in the early phase ${ }^{21}$.
Procedural success of this case is a great learning and will aid to undertake such procedure in other cases of post myocardial infarction VSR in future.

\section{Conclusion}

Ventricular septal rupture is a lethal complication of acute myocardial infarction. Transcatheter closure of ventricular septal rupture is a reasonable therapeutic option for post myocardial infarction ventricular septal rupture.

\section{Conflicts of Interest}

The authors declare no conflicts of interest regarding the publication of this paper.

\section{References}

1. Shah SH, Shah MA, Ghanem A, Shaheen S, Akleh S, Vamvakidou A, et al. Post-myocardial infarction ventricular septal rupture in a patient with large secundum atrial septal defect: a case report. European Heart Journal - Case Reports. 2019;3(2). ytz042. 10.1093/ehjcr/ytz042

2. Moreyra AE, Huang MS, Wilson AC, Deng Y, Cosgrove NM, Kostis JB. Trends in incidence and mortality rates of ventricular septal rupture during acute myocardial infarction. Am J Cardiol. 2010; 106: 1095-1100. 10.1016/j. amjcard.2010.06.013.

3. Cannon CP, Brindis RG, Chaitman BR, Cohen DJ, Cross JT Jr, Drozda JP Jr, et al. 2013 ACCF/AHA key data elements and definitions for measuring the clinical management and outcomes of patients with acute coronary syndromes and coronary artery disease: a report of the American College of Cardiology Foundation/American Heart Association Task Force on clinical data standards (writing committee to develop acute coronary syndromes and coronary arterydisease clinical data standards). J Am Coll Cardiol. 2013; 61: 992-1025. 10.1161/CIR.0b013e3182831a11.

4. Arnaoutakis GJ, Zhao Y, George TJ, Sciortino CM, McCarthy PM, Conte JV. Surgical repair of ventricular septal defect after myocardial infarction: outcomes from the Society of Thoracic Surgeons National Database. Ann Thoracic Surg. 2012;94:436-43. 10.1016/j.athoracsur.2012.04.020

5. Menon V, Webb JG, Hillis LD, Sleeper LA, Abboud R, Dzavik V, et al. Outcome and profile of ventricular septal rupture with cardiogenic shock after myocardial infarction: a report from the SHOCK Trial Registry. SHould we emergently revascularize Occluded Coronaries in cardiogenic shock? J Am Coll Cardiol. 2000;36:1110-6. 10.1016/s07351097(00)00878-0

6. Shabestari MM, Ghaderi F, Hamedanchi A. Transcatheter closure OF Postinfarction ventricular Septal Defect: A case report and review of literature. Journal of Cardiovascular and Thoracic Research. 2015;7(2):75-7. 10.15171/jcvtr.2015.17

7. Mubarik A, Iqbal AM. Ventricular Septal Rupture. In: StatPearls [Internet]. Treasure Island (FL): Stat Pearls Publishing; 2021 Jan-. Available from: https://www.ncbi.nlm. nih.gov/books/NBK534857/

8. Hachida M, Nakano H, Hirai M, et al. Percutaneous transaortic closure of postinfarction ventricular septal rupture. Ann Thor Surg. 1991; 51: 655-57.

9. Szkutnik M, Bialkowski J, Kusa J, Banaszak P, Baranowski J, Gąsio M, et al. Postinfarction ventricular septal defect closure with Amplatzer occluders. Eur J Cardiothorac Surg 2003; 23: 323-7. doi:10.1016/S1010-7940(02)00812-6 
10. Calvert PA, Cockburn J, Wynne D, Ludman P, Rana BS, Northridge D, et al. Percutaneous closure of postinfarction ventricular septal defect: in-hospital outcomes and long-term follow-up of UK experience. Circulation 2014; 129: 2395-402. 10.1161/CIRCULATIONAHA.113.005839

11. Cruz-González I, Barreiro-Pérez M, Sánchez P. Device closure of a ventricular Septal rupture in a patient on ECMO. Revista Española de Cardiología (English Edition). 2018;71(11):973. 10.1016/j.rec.2017.11.012

12. Holzer R, Balzer D, Amin Z, Ruiz CE, Feinstein J, Bass J, et al. Transcatheter closure OF postinfarction ventricular SEPTAL defects using the new AMPLATZER Muscular vsd Occluder: Results of a U.S. Registry. Catheterization and Cardiovascular Interventions. 2004;61(2):196-201. 10.1002/ ccd. 10784

13. Ahmed J, Ruygrok PN, Wilson NJ, Webster MWI, Greaves S, Gerber I. Percutaneous closure OF Post-Myocardial Infarction ventricular septal defects: A Single centre Experience. Heart, Lung and Circulation. 2008;17(2):119-23. 10.1016/j. hlc.2007.09.001

14. Tai S, Tang J-jun, Tang L, Ni Y-qing, Guo Y, Hu X-qun, et al. Management and outcome of ventricular septal rupture complicating acute myocardial infarction: What is new in the era of percutaneous intervention? Cardiology. 2018;141(4):226-32. https://doi.org/10.1159/000495877

15. Deja MA, Szostek J, Widenka K, Szafron B, Spyt TJ, Hickey MS et al.Post infarction ventricular septal defect — can we do better? Eur J Cardiothorac Surg 2000; 18: 194-201. 10.1016/ s1010-7940(00)00482-6

16. Thiele H, Kaulfersch C, Daehnert I, Schoenauer M, Eitel I, Borger M, et al. Immediate primary transcatheter closure of postinfarction ventricular septal defects. European Heart Journal. 2009;30(1):81-8. 10.1093/eurheartj/ehn524

17. Zhu XY, Qin YW, Han YL, Zhang DZ, Wang P, Liu YF, et al. Long-term efficacy of transcatheter closure of ventricular septal defect in combination with percutaneous coronary intervention in patients with ventricular septal defect complicating acute myocardial infarction: a multicentre study. Euro Intervention. 2013;8(11):1270-6. 10.4244/ EIJV8I11A195

18. Xu XD, Liu SX, Liu X, Chen Y, Li L, Qu BM, et al. Percutaneous closure of postinfarct muscular ventricular septal defects: a multicenter study in China. J Cardiol. 2014;64(4):285-9. 10.1016/j.jjcc.2014.02.006

19. Shafiei I, Jannati F, Jannati M. Optimal time repair of ventricular septal rupture post myocardial infarction. Journal of the Saudi Heart Association. 2020;32(2):288-94. $10.37616 / 2212-5043.1120$

20. Premchand RK, Garipalli R, Padmanabhan TNC, Manik G. Percutaneous closure of post-myocardial infarction ventricular Septal rupture - a single centre experience. Indian Heart Journal. 2017;69. 69 Suppl 1: S24-S27. 10.1016/j. ihj.2016.10.004

21. Laxman D. Ventricular septal Rupture complicating acute myocardial infarction in a tertiary care Hospital of Nepal. J Cardiovasc Med Cardiol 2017; 4(1):013-6. http://doi. org/10.17352/2455-2976.000040 